stems. The stalked pods are oval, flat, broadly winged and deeply notched at the tip. Generally green at first, the pods turn dull-yellow to orange when mature. The seeds are a purplish chocolate brown with a grooved pattern like a finger print on each side.

The stinkweed is especially detrimental in fields where dairy cows are pastured because, if grazed, it imparts a disagreeable, somewhat garlic-like flavor and odor to the milk.

Shepherd's purse (Capsella bursapastoris) also belongs to the Cruciferae or Mustard Family. The Latin name is literally a shepherd's little purse, an allusion to the shape of the tiny seed pods. This introduced annual or winter annual has a branched stem with small white flowers in branched racemes. The basal leaves are often deeply cut and lobed, forming a rosette. The stem leaves are small, lance-shaped and clasp the stem with eared bases. The pods are an inverted triangle and notched at the blunt end. Each pod contains about twenty small seeds. Shepherd's purse is a very common weed on roadsides around dwellings and in waste places.

\section{ORCHID SURVEY}

A group of members of the Ottawa Field-Naturalists' Club have begun a long-term project to accumulate sight records of occurrences of native Canadian orchids. During the summer of 1966 three teams of observers located 37 species of orchids in 913 localities within driving distance of Ottawa. It is hoped that the survey can take place in all parts of Canada.

Knowledge of the distribution of orchids obtained from the survey could be used in connection with preservation activities, especially near our more urbanized regions. If it is known, for example, that a particular locality contains a rare species or that the locality contains many species a stronger case can be made for leoal preservation or protection of the site. Sites rich in orchids often contain other rare or interesting kinds of plants. The presence of such plants can provide further justification for establishing legal protection for such sites.

Maps of the National Topographic System marked with 1000-metre grid must be used for the survey. These maps, scale $1: 50,000$, can be obtained for 50 cents each from: Maps Distribution Office, Department of Energy, Mines and Resources, 615 Booth Street, Ottawa 4, Ontario. Make cheque or money-order payable to the Receiver-General of Canada. Participants from all parts of Canada are cordially invited. For more details write to project coordinator, $M r . E$. W. Greenwood, P.O. Ramsayville, Ontario.

\section{OYSTER MUSHROOM}

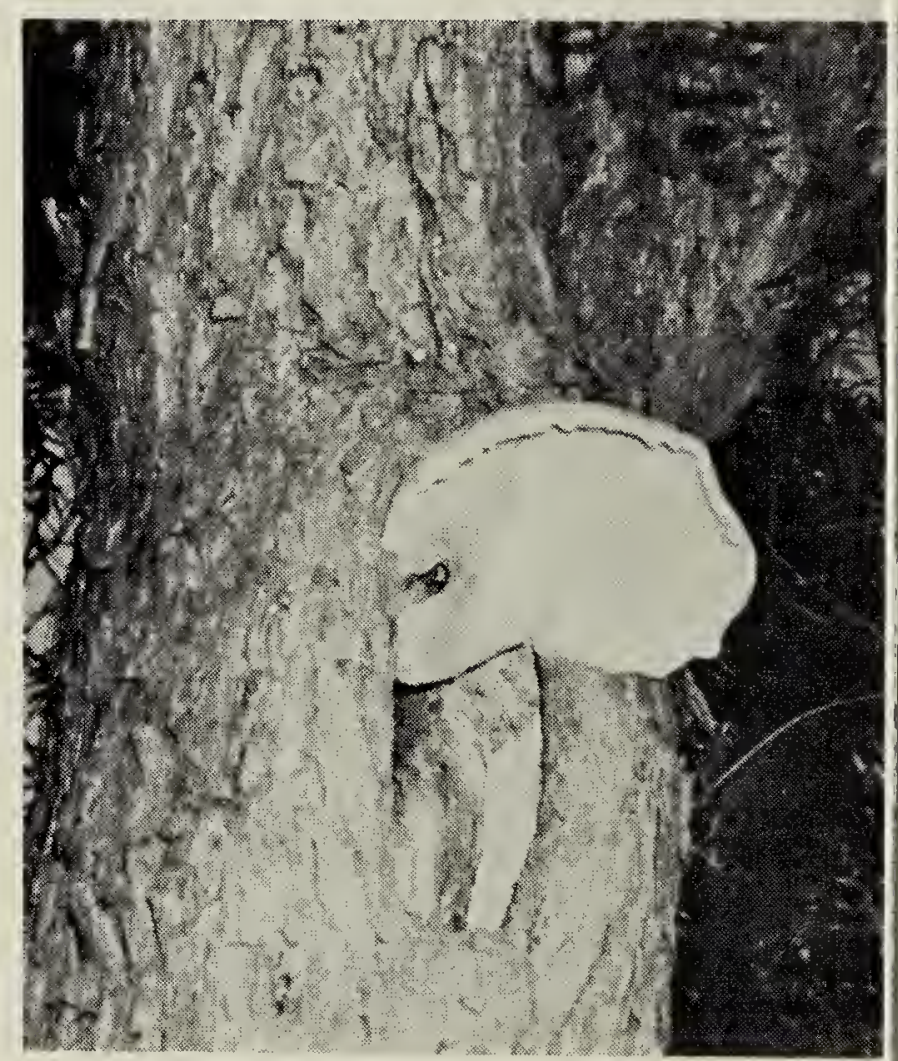

The Oyster Mushroom is reported as "delectable when not too old". In the accompanying picture the Oyster Mushroom, Pleurotus ostreatus, is shown growing above a natural cavity in a Pepper Tree, Schinus molle. My daughter Marjorie and I found this rather unique "set-up" while taking 1966 Christmas bird census. We thought that the mushrooms made good protective canopy over a suit. able nesting or roosting place for birds.-Emerson A. Stoner, Benicia California. 